\title{
Current Status of Ancylostoma Species in Domestic and Wild Animals and Their Zoonotic Implication: Review
}

\author{
Merga Daba ${ }^{1, ~ *, ~ M i s g a n a ~ N a r a m o ², ~ G e l a n a ~ H a i l e ~}{ }^{1}$ \\ ${ }^{1}$ Animal Health Department, Alage Agricultural Technical and Vocational Education and Training College, Alage, Ethiopia \\ ${ }^{2}$ Livestock and Fisheries Resources Office, Shone, Ethiopia
}

Email address:

sofimerga@gmail.com (M. Daba)

${ }^{*}$ Corresponding author

To cite this article:

Merga Daba, Misgana Naramo, Gelana Haile. Current Status of Ancylostoma Species in Domestic and Wild Animals and Their Zoonotic Implication: Review. Animal and Veterinary Sciences. Vol. 9, No. 4, 2021, pp. 107-114. doi: 10.11648/j.avs.20210904.14

Received: July 26, 2021; Accepted: August 6, 2021; Published: August 13, 2021

\begin{abstract}
Hookworm species are mainly an endo-parasite of cats and dogs and others animals including man. Next to roundworm (Ascaris suum) and whipworm (Trichuris trichuria) infections, hookworm infections ranked third in terms of disease load in humans. Among hookworms, Ancylostoma species are highly prevalent in various species of domestic and wild animals, including humans, and mostly found in Asia and tropical countries. People who live in poor resource countries are more vulnerable than in developed countries. Hookworms in children cause mental impairment that leads to cognitive impairment. Similarly, a disability-adjusted life year (DALY) occurs in hookworms, particularly Ancylostoma infects children due to physical impairment. In animals, hookworm may cause diarrhea, stunted growth, and anemia and even lead to death in young animals. Furthermore, Ancylostoma causes cutaneous larva migrans, eosinophilic enteritis, and anemia and finally may cause death in humans. As a result of urbanization, climate change, and land degradation, there are various Ancylostoma species which are newly emerging in animals. Currently, the Ancylostoma is a great concern both in humans and animals, particularly in resource poor countries. The Ancylostoma infection may require governmental and public attention. Therefore, a control and prevention strategy strongly requires integration between medical and veterinary communities to improve environmental and personal hygiene.
\end{abstract}

Keywords: Ancylostma Species, Anemia, Domestic Animals, Hookworm, Wild Animals

\section{Introduction}

Soil transmitted gastro intestinal helminth infections are common in less developed countries and in the world's poorest populations. Approximately 2 billion of the world's populations suffer from soil-transmitted helminthes infection. 576-740 million people were affected by hookworms worldwide. In Sub-Saharan Africa, Americas, China, and East Asia are the areas where this infection is most prevalent [1]. Hookworms are blood sucking nematodes that live in the digestive tracts of mammals. It has significant importance both in animals and humankind. Initially, the word Ancylostoma came from the Greek words ankulos (hooked or crooked) and stoa (mouth), which refer to the worm's identification structures [2]. Hookworms are highly prevalent in humans with mixed infections during the summer-autumn period [3]. Hookworms are one of the blood-sucking nematode parasites that use a sharp cutting device at the anterior end for attachment to the mucosa and sub-mucosa of the intestine and suck into their buccal chambers a tissue plug [4]. Hookworms are able to initiate and maintain bleeding through capillaries and arterioles rupture due to mechanical damage and chemical activity by hydrolytic enzymes. Hookworms also secrete a range of anticlotting substances to ensure blood flows freely [5].

The adult worms suck impulses up to $120-150$ per minute and are known as greedy blood suckers through the help of persistent esophagus movements. A worm can suck $0.2 \mathrm{ml}$ of blood per day [6]. Hence, people are infected by hookworm globally, leading to physical and mental growth retardation and anemia [4, 7]. Disability-adjusted life years (DALY) frequently happen due to physical impairment than death occurs [7].

Ancylostoma species is one of the most important soil transmitted helminth parasites in a variety of animal species, 
including man. Ancylostoma species are categorized under the family of Ancylostomatidae. Host infection by Ancylostoma species could be via fecal-oral route or skin penetration of the third-stage larvae [7]. However, transmammary infection was described in bitches during the pregnancy period and rarely ingestion of paratenic hosts (rodents) which is common in Ancylostoma caninum [8, 9].

Anemia, retarded growth, tissue injury, inflammation, and mortality are the main pathological effects of hookworm infections in several wildlife and domestic species [10]. There are some species of Ancylostoma species that transmit from animal to human directly or indirectly by means of transmission. The most important species of Ancylostoma species which are responsible for human infections are Ancylostoma caninum, Anylostoma ceylanicum, and Ancylostoma braziliense. Larval migrans in humans were repeatedly reported by $A$. caninum and A. braziliense [11].

Currently, some of the Ancylostoma eggs and adult parasites of cats and dogs have been detected in the human intestine. The main hookworms in cats and dogs that can affect humans are $A$. ceylanicum and $A$. caninum. The diagnosis of Ancylostoma species based on egg morphology was not a convenient and accurate method for differentiation. Ancylostoma species identification based on morphological features has some disadvantages in terms of human labour, wasting time and demanding skilled personnel. Due to mixed infection, there is always the risk of being overlooked [12].

A previous study reported that orally administration of a combination of pyrantel, febantel, and praziquantel was found to be helpful in dogs with chronic illness [13]. It is frequently ineffective at eliminating adult worms from the host intestine [14]. Oral admistration of Ivermectin is an effective drug with a single oral dose of $12 \mathrm{mg}$ for humans during cutaneous larval migrans that cures $100 \%$ [15]. Albendazole and Mebendazole are effective for clearing adult parasites from human intestines for consecutive 1-3 days with an iron supplement [16].

Currently, prevention and control of zoonotic hookworms are becoming serious challenges for various reasons, like, lack of restricted movement of canine and feline animals to social recreational places, walking barefoot, over intimacy with pet animals, and lack of community awareness. In this regard, there is a scarcity of compiled information of Ancylostoma species infections in domestic and wild animals as well as in humans. Therefore, this review highlighted and summarized the prevalence and zoonotic importance of Ancylostoma species in domestic and wild animals currently circulating in resource-poor and deprived countries.

\section{Morphology and Taxonomic Classification}

The eggs of hookworm are thin and single membrane which can be broken down throughout the passage of the human stomach. Almost all hookworm eggs, including $A$. caninum, seem to have an oval shape and are about $50 \mu \mathrm{m}$ in diameter. The egg seems like a morula containing a group of cells with an elliptical shape and smooth shell. The finding demonstrated that the eggs of $A$. caninum and A. tubaeforme were larger than those of $A$. braziliense [17]. The adult parasite of $A$. caninum is different from other species by three pairs of prominent teeth on the ventral side (figure 1).

The presence of three teeth on either side of the ventral midline distinguishes the adults of $A$. tubaeforme from those of $A$. braziliense and A. ceylanicum. A. brazileinse and $A$. ceylanicum have two teeth $[11,18]$. At the anterior end of the buccal cavity of $A$. ceylanicum, a pair of large teeth on top and a pair of smaller teeth below are proportionally found. The oral hole is larger and round-shaped as compared to $A$. braziliense. The ventral, dorsal, and lateral rays of $A$. ceylanicum are found in the copulatory bursa [19]. The presence of three pairs of teeth in the buccal cavity was used to identify A. caninum morphologically [20].
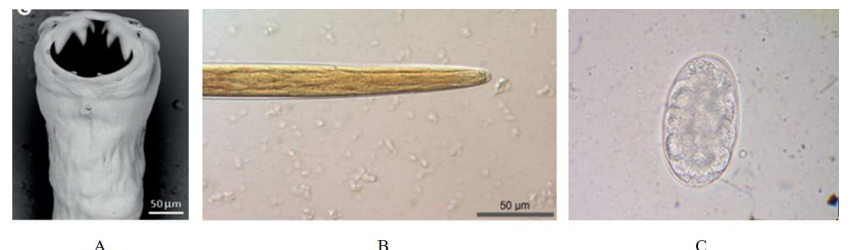

Figure 1. A) Morphology of A. caninum, with its 'teeth' clearly visible [1, 2]. B) Filariform esophagus on the anterior of an infective third-stage larva. C) Ancylostoma caninum egg found in the fecal sample of a dog, microscope at $1000 X$

Taxonomy of Ancylostoma species are classified under class of nematode which is important to indicate the genetically relationship of the different species, systems of taxonomy has been developed (Figure 2).
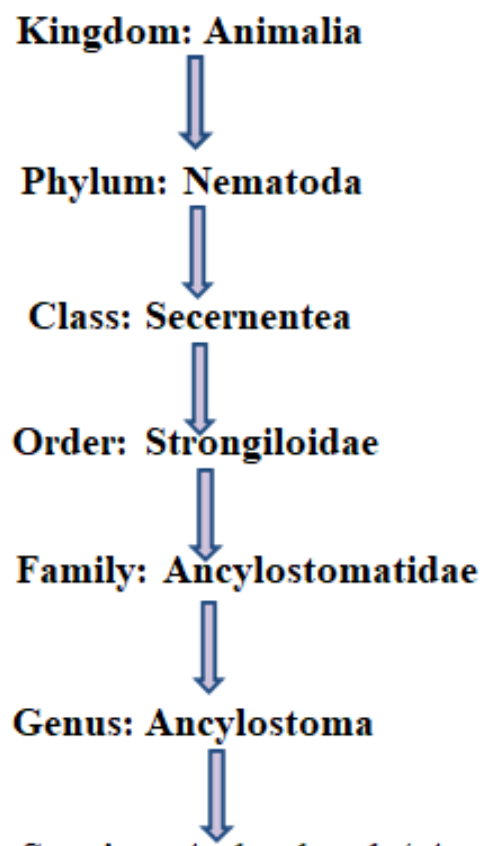

Species: A. duodenale/ A.caninum

Figure 2. Taxonomic classification of Ancylostomatidae. (http://www.ncbi.nlm.ni h.gov/genome/? Term $=N+$ americanus). 


\section{Zoonotic Ancylostoma Species of Animals}

\subsection{Ancylostoma caninum}

Ancylostoma caninum infection is characterized by eosinophilic enteritis and intestinal hypersensitivity [22]. Ancylostoma caninum mainly infects dogs and rarely cats, including humans. Cutaneous larva migrans is common in humans [23] or enteric infections in people with eosinophilic enteritis $[22,24]$. Follicular dermatitis is also common in humans [25]. There is a phenomenon called "larval leak" in A. caninum, particularly in dogs, in which larvae leak from arrested/hypobiotic stages (tissue) to adult stages in the intestine [26, 27]. In these cases, dogs continue to shade hookworm eggs due to new leak out of larval from inactivated form. Even during treatment with anthelmintic, the egg shedding stops for a few days. When the duration of treatment is completed, the eggs also reappear continuously [28].

Ancylostoma caninum can mature from eggs to adults in the human intestine. However, this may occur in a rare condition. An $A$. caninum infection in humans has been documented in Australia [22]. Adult A. caninum was detected in a man of 60 years old upon health examination in South Korea [20]. Hookworm eggs were found in human feces in recent research in South Africa [29] and India [30].

\subsection{Ancylostoma ceylanicum}

One of the zoonotic hookworms which may develops into adult stage in human intestine. Ancylostoma ceylanicum is one of commonly known hookworm of domestic dogs and cats all over Asian countries [3-5]. Ancylostoma ceylanicum was reported from India for the first time [6]. Ancylostoma cyelanicum has been found in domestic dogs in Western Australia, Victoria, Queensland, and the Northern Territory [7]. A new case of $A$. ceylanicum was reported in France from traveller who returned from tropical countries [8]. Human infection of A. ceylanicum was also reported from Vietnam by molecular identifications [9].

In humans, this parasite was reported from Western Australia [10]. Ancylostoma ceylanicum was even reported in humans and dogs in Laos and Thailand. Study conducted in Philippines (Palapag and Laoang) indicated that human were positive of $A$. ceylanicum [11]. The symptoms manifested in human are long-lasting abdominal disorder $[3,4]$. The following clinical signs are suggestive of being infected by $A$. ceylanicum such as, eosinophilia, transient ground itch, weakness, weight loss, fever, diarrhoea, melena, nausea, and vomiting and difficulty in breathing. Blood loss and iron-deficiency anemia is aggravated in children and pregnant women. In dogs, heavy infections lead to blood loss which revealed by microcytic hypochromic iron-deficiency anemia [12].

\subsection{Ancylostoma tubaeforme}

Ancylostoma tubaeforme are found most commonly in canids, felids, and humans and have significant zoonotic importance. It is highly prevalent in warmer areas of the world [40]. According to previous reports, cats were highly infected by A. tubaeforme and dermatitis is the symptoms of Ancylostoma tubaeforme infection [41], anemia, pulmonary lesions and weight loss also reported [28].

The larvae of $A$. tubaeforme can infect a host through oral intake or cutaneous penetration. Ingested larvae enter the stomach via the eosophagus and, eventually, larvae develop into adults beneath the layer of duodenum and stomach. Those adult hookworms lay eggs in the intestines which they propel to the outside with feces. The infective larvae mature in the environment before infecting a host by skin penetration. After skin penetration, the larvae migrate to the lungs and then move up to the trachea, and down to the esophagus, ultimately reaching the stomach [28]. The total pre-patent period of this hookworm is about 22-25 days [41].

\subsection{Ancylostoma braziliense}

Ancylostoma braziliense is also hookworm of the cats and dogs and lives in intestines. Anemia may occur due to consistent sucking of blood from cats and dogs intestines by adult hookworm [13]. This species is indigenous to the Southern United States, but it can also be found in subtropical locations around the world, such as Central and South America and Southern Asia. Distribution of Ancylostoma in Southern Asia is limited to Indonesia, Borneo, and Malaysia [4]. Humans are infected by $A$. braziliense parasites but not true definitive hosts. The immature larvae only migrate to beneath the epidermis, producing lesions. Those immature larvae ultimately dies, could not travel to circulatory system or reaching adult stages in the intestine $[14,15]$.

\section{Life Cycle of Ancylostoma Species}

Adult male and female hookworms mate in the intestine at the start of their life cycle (figure 3 ). The adult female then lays an egg, which is passed through the feces and hatches in the environment. The L1 feeds on cells of bacteria and then moults twice to generate non-feeding, eventually develop to L3. Infective L3 molts twice before reaching adult stage in the small intestine, infection may happen by epidermis penetration or ingestion of paratenic hosts such as rats. In $A$. caninum, the larval developmental arrest (hypobiosis) in the host after L3 reached to skeletal or intestinal muscle [16]. Due to increase transforming growth factor, the hypobiotic L3 would be initiated the reactivation and travels to the mammary gland in pregnant females [46]. Newly born pups get infected via colostrum/milk of bitch with infective larvae [9]. In paratenic or transport hosts like rodents and insects musle, L3 development of hookworm remains in hypobiotic stages. Ancylostoma caninum larvae were detected in mice, cats, and monkeys [47]. 


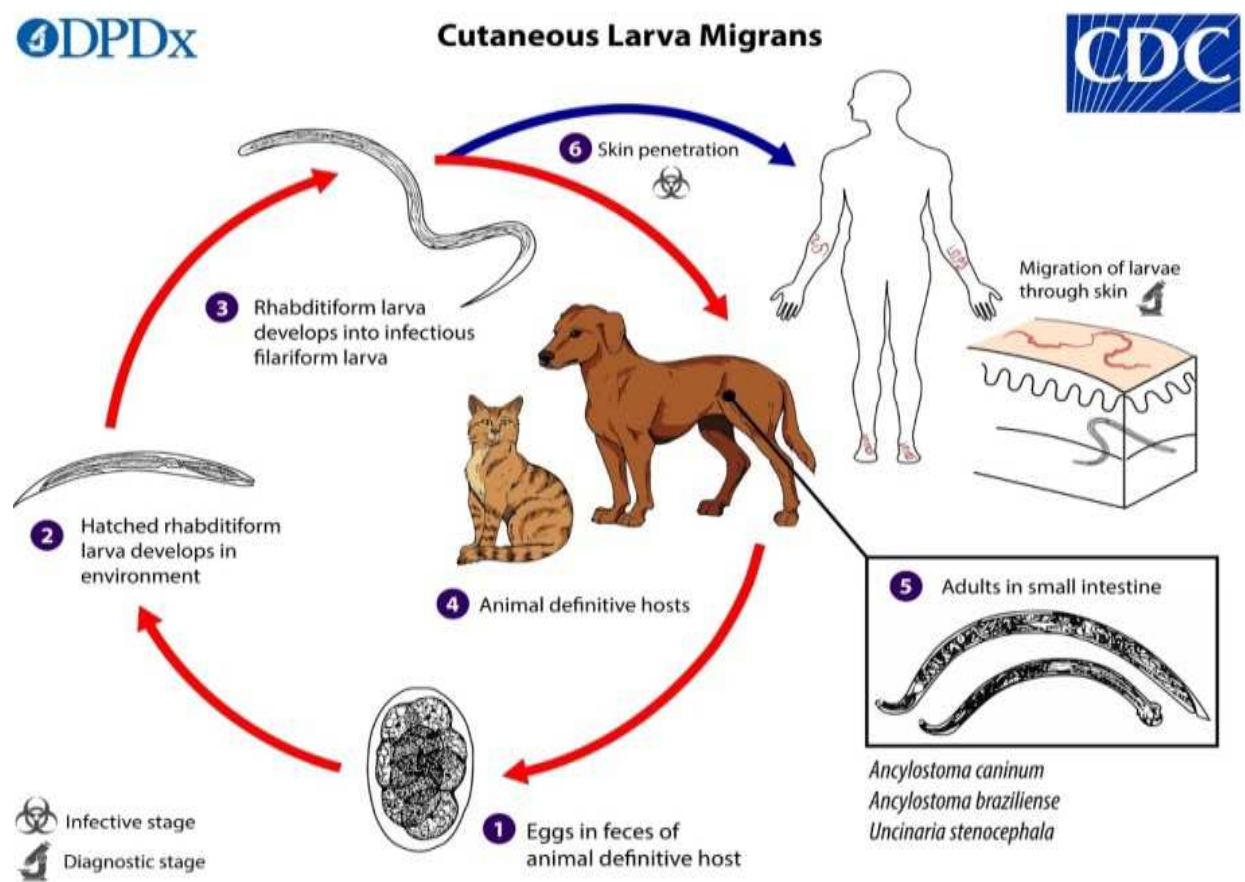

Figure 3. Ancylostoma species and canine hookworm life cycle. (https://www.cdc.gov/dpdx/zoonotichookworm/index.html).

\section{Geographical Distribution of Ancylostoma Species in Wild Animals}

There are newly emerging parasitic nematodes in wild life due to alteration of land scenery, climate change, increased urbanization, and human wildlife interaction. Furthermore, the establishment of zoological gardens for endangered and valued animals has the potential to change natural hostparasite dynamics $[48,49]$. As a result, hookworm species such as A. tubaeforme, A. pluridentatum, A. braziliense, and human hookworms like $N$. americanus have a wide host range of wild animals [10]. Ancylostoma species infect wild animals as a result of over flow from domestic animals [50]. The importance of animal-human-wildlife interaction in disease transmission particularly, in spillover and spillback that is important in the maintenance of hookworm in wildlife and domestic animals [10]. The dynamics of nematode infections in wild animals may be influenced by changes in landscapes and climate change [48]. Ancylostoma species can be found in wild animals all over the world reported as summarized (Table 1) below.

Table 1. Summary of reported Ancylostoma species in wild animal.

\begin{tabular}{|c|c|c|c|}
\hline Ancylostoma Species & Hosts & Country & References \\
\hline A. kusimaense & Nyctereutes procyonoides, raccoon dog, red foxes & Asia & {$[17,18]$} \\
\hline A. Malayanum & Bears & Japan & [19] \\
\hline A. lotoris, & Black bears & South eastern United State & [20] \\
\hline A. lotoris & Skunks & North America & [21] \\
\hline A. conepati & Skunk, Conepatus chinga & South America & [22] \\
\hline A. duodenale & Spotted hyenas & Ethiopia & [23] \\
\hline Ancylostoma sp. & Hyena & Kenya & [24] \\
\hline A. ceylanicum & Malay civet & Malaysia & [25] \\
\hline Ancylostoma sp. & Cercopithecids & Cameroon & [26] \\
\hline A. caninum, A. pluridentatum A. tubaeformae, A. braziliense & Bobcat and Cougars & South eastern United States & [27-29] \\
\hline A. buckleyi & Crab-eating fox, Pampas fox & State of São Paulo, Brazil & {$[30,31]$} \\
\hline A. braziliense, A. ceylanicum, A. caninum & Dingo & Cairns, Far North Queensland & [32] \\
\hline A. caninum & Golden Jackal & Hungary & {$[33,34]$} \\
\hline A. pluridentatum & Jaguar & Colombia and Panama & [35] \\
\hline A. tubaeforme & Persian Leopard & Iran & [36] \\
\hline A. ailuropodae & Wild giant pandas & Southwest China & [37] \\
\hline A. buckleyi & Pampas foxes & Southern South America & {$[30,31]$} \\
\hline A. tubaeforme & Feral cats & Southeastern Mexico & [38] \\
\hline A. caninum & Wolves & Poland & [39] \\
\hline A. caninum & Red fox and Jackal & Tunisia & {$[30,31]$} \\
\hline A. kusimaense & Raccoon dogs & Japan & {$[30,31]$} \\
\hline A. caninum & Red fox & Denmark & [40] \\
\hline A. caninum & Wild dog & South Africa & [41] \\
\hline
\end{tabular}




\section{Prevalence and Geographical Distribution of Ancylostoma Species in Domestic Animals}

Nematodes are among the gastrointestinal zoonotic parasites that can be found in dogs and cats [42]. Carnivores are usually definitive hosts, and they help to spread zoonotic infection by dispersing infective eggs or larvae throughout the environment. In felids and domestic animals, Ancylostom $a$ species parasitizes the small intestine. Ancylostoma species are prevalent in Sub-Saharan Africa, Americas, China, and East Asia (Table 2).

Table 2. Prevalence of Ancylostoma species from domestic animals in different countries of the world.

\begin{tabular}{|c|c|c|c|c|c|}
\hline Country & Animal spp & Prevalence $(\%)$ & Spp. identified & Test method & References \\
\hline \multirow{5}{*}{$\begin{array}{l}\text { China/ } \\
\text { Guangdong }\end{array}$} & Dog & 33.1 & A. ceylanicum & PCR & \multirow{5}{*}[42]{} \\
\hline & Cat & 51.1 & A. ceylanicum & & \\
\hline & Dog & 59.9 & A. caninum & & \\
\hline & Cat & 48.9 & A. tubaeforme & & \\
\hline & Dog & 7 & Mixed infections & & \\
\hline \multirow{3}{*}{$\begin{array}{l}\text { Mexico } \\
\text { China/ } \\
\text { Guangzhou }\end{array}$} & Dog & 73.8 & A. caninum & \multirow{3}{*}{$\begin{array}{l}\text { light microscopy } \\
\text { PCR-RFLP }\end{array}$} & [43] \\
\hline & Cat & 95.1 & A. caninum & & \multirow{2}{*}{ [44] } \\
\hline & Cat & 40.2 & Mixed $A$. caninum \& A. ceylanicum & & \\
\hline \multirow{2}{*}{ Malaysia } & Dog & 52 & ceylanicum & \multirow{3}{*}{ Formal-ether \& PCR } & \multirow{3}{*}{ [45] } \\
\hline & & 48 & A. caninum & & \\
\hline \multirow{3}{*}{ Vietnam } & & 54.3 & A. ceylanicum & & \\
\hline & Dog & 33 & A. caninum & \multirow[t]{2}{*}{ PCR-RFLP } & \multirow[t]{2}{*}[46]{} \\
\hline & & 12.7 & Mixed $A$. caninum \& A. ceylanicum & & \\
\hline China/Heilongjiang & Dog & 66.3 & A. caninum & Morphological keys and descriptions & [47] \\
\hline \multirow[t]{2}{*}{ Brazil /São Paulo State } & \multirow[t]{2}{*}{ Dogs } & 12.5 & A. braziliense & \multirow{2}{*}{ PCR } & \multirow[t]{2}{*}[48]{} \\
\hline & & 26.1 & mixed $A$. caninum \& $A$. braziliense & & \\
\hline Iraq/ Basra & Dogs & 7.5 & A. caninum & Centrifugal flotation & [49] \\
\hline \multirow{4}{*}{ Malaysia /Klang Valley } & \multirow{2}{*}{ Cat } & 29.6 & A. ceylanicum & \multirow{4}{*}{ PCR-HRM } & \multirow{4}{*}[50]{} \\
\hline & & 6.6 & A. caninum & & \\
\hline & \multirow{2}{*}{ Dogs } & 44.5 & A. ceylanicum & & \\
\hline & & 8.8 & A. caninum & & \\
\hline Iran/Mazandaran & Dogs & 41.2 & A. caninum & Sheather's flotation \& PCR & [51] \\
\hline Sudan /Shendi & Dogs & 0.8 & A. caninum & flotation \& microscope & {$[52]$} \\
\hline Ethiopia & Dogs & 14.7 & Ancylostoma spp & Formole ether concentration & [53] \\
\hline Brazil/ Seropédica & Dogs & 13.6 & A. caninum & Flotation by centrifuge ation-flotation & {$[54]$} \\
\hline Mexico/ Tabasco & Dogs & 15.9 & A. caninum & Centrifugal flotation & {$[54]$} \\
\hline Italy/ Teramo & Dogs & 0.6 & Ancylostoma spp & Floatation sodium nitrate solution & {$[55]$} \\
\hline Japan & Dogs & 0.2 & A. caninum & Formalin-ethyl acetate sedimentation & {$[56]$} \\
\hline Northern Thailand & Dogs & 82.1 & A. ceylanicum & Sucrose flotation \& PCR & {$[57]$} \\
\hline Uruguay/ Tacuarembo & & 96.3 & A. caninum & $10 \%$ formalin. & {$[58]$} \\
\hline USA/ Georgia & Cat & 11.7 & Ancylostoma sp. & Centrifugation sugar flotation & [59] \\
\hline Northern mississippi & Cat & 34 & Ancylostoma sp. & Fecal flotation & {$[60]$} \\
\hline Czech Republic /Prague & Dogs & 0.4 & Ancylostoma sp. & Fecal flotation & [61] \\
\hline & & 36 & A. caninum & & \\
\hline North eastern India & Dogs & 24 & braziliense & PCR-RFLP & {$[62]$} \\
\hline Notill Castentilitila & & 38 & $\begin{array}{l}\text { Mixed infection A. caninum \& } A \text {. } \\
\text { braziliense }\end{array}$ & PCK-KFLP & \\
\hline
\end{tabular}

PCR- polymerase chain reaction; RFLP- Restriction Fragment Length Polymorphism; HRM-High resolution melting analysis

\section{Prevention and Control Measures}

Creation of awareness about zoonotic Ancylostoma species among rural communities and municipal offices is the most important point of prevention and control. Hence, a periodic deworming of pet animals and communities awareness to wear shoes outdoors have a key role in prevention. Regular deworming of pet animals should be strongly mandatory to reduce the risk of transmission to humans. Prior domestic and international movement of dogs, implementation of laws for restraining stray dogs, routine parasitic examination and treatment need to be strictly executed $[63,64]$. A one health approach is the best methods to address long-term control of zoonotic hookworm. Moreover, deworming with Albendazole and Mebendazole in human populations on a regular basis can help to minimize morbidity [39]. In order to control 
hookworm infection in the communities, proper hygiene and sanitation could play an essential role [65].

\section{Conclusions and Recommendations}

Currently, the hookworm is a commonly found in humans and animals, particularly in resource poor countries. Ancylostoma species are the most common zoonotic hookworms which transmit from animals to humans. The Ancylostoma species has a significant impact on the physical and mental growth of children from resource-deprived countries. Hence, based on above conclusions the following recommendations are forwarded: the integrated approach between human and veterinary worker is necessary to prevent and control Ancylostoma species in endemic countries. The following measures need to be implemented, such as awareness creation in communities, restriction of animals (feline and canine) from recreational areas, avoiding walking on bare feet, regular deworming of pets and humans, and maintaining proper personal and environmental hygiene and sanitation and further studies on hookworm vaccine develop ment and molecular epidemiology have significant role in prevention and control.

\section{References}

[1] Loukas, A.; Hotez, P. J.; Diemert, D.; Yazdanbakhsh, M.; McCarthy, J. S.; Correa-Oliveira, R.; Croese, J.; Bethony, J. M. Hookworm infection. Nature reviews. Disease primers 2016, 2, 16088, doi: 10.1038/nrdp.2016.88.

[2] Hawdon, J. M.; Wise, K. A.; Strube, C.; Mehlhorn, H. e., vol Ancylostoma caninum and Other Canine Hookworms Dog Pa rasites Endangering Human Health. Parasitology Research Monographs. Springer, Cham 2021, 13. doi: https: //doi.org / 10.1007/978-3-030-53230-7_9.

[3] Conlan, J. V.; Khamlome, B.; Vongxay, K.; Elliot, A.; Pallant, L.; Sripa, B.; Blacksell, S. D.; Fenwick, S.; Thompson, R. C. Soil-transmitted helminthiasis in Laos: a community-wide cross-sectional study of humans and dogs in a mass drug administration environment. The American journal of tropical medicine and hygiene 2012, 86, 624-634, doi: 10.4269/ajtmh.2012.11-0413.

[4] Traub, R. J.; Inpankaew, T.; Sutthikornchai, C.; Sukthana, Y.; Thompson, R. C. PCR-based coprodiagnostic tools reveal dogs as reservoirs of zoonotic ancylostomiasis caused by Ancylostoma ceylanicum in temple communities in Bangkok. Veterinary parasitology 2008, 155, 67-73, doi: 10.1016/j.vetpar.2008.05.001.

[5] Yoshida, Y.; Okamoto, K.; Chiu, J. K. Ancylostoma ceylanicum infection in dogs, cats, and man in Taiwan. The American journal of tropical medicine and hygiene 1968, 17, 378-381, doi: 10.4269/ajtmh.1968.17.378.

[6] Lane, C. Ancylostoma Ceylanicum, a New Human Parasite. The Indian medical gazette 1913, 48, 217-218.

[7] Palmer, C. S.; Traub, R. J.; Robertson, I. D.; Hobbs, R. P.; Elliot, A.; While, L.; Rees, R.; Thompson, R. C. The veteran ary and public health significance of hookworm in dogs and cats in
Australia and the status of $A$. ceylanicum. Veterinary parasitology 2007, 145, 304-313, doi: 10.1016/j.vetpar.2006 .12.018.

[8] Gerber, V.; Le Govic, Y.; Ramade, C.; Chemla, C.; Hamane, S.; Desoubeaux, G.; Durieux, M.-F.; Degeilh, B.; Abou-Bacar, A.; Pfaff, A. W.; et al. Ancylostoma ceylanicum as the second most frequent hookworm species isolated in France in travellers returning from tropical areas. Journal of Travel Medicine 2021, doi: 10.1093/jtm/taab014.

[9] Bui, K. L.; Nguyen, T. H.; Duong, H. D.; Nguyen, V. L.; Nguyen, T. N.; Le, L. A.; Cong, H. M.; Tran, K. T.; Le, D. V.; Nagayasu, E.; et al. Ancylostoma ceylanicum infections in humans in Vietnam. Parasitology international 2021, 84, 102405, doi: 10.1016/j.parint.2021.102405.

[10] Koehler, A. V.; Bradbury, R. S.; Stevens, M. A.; Haydon, S. R.; Jex, A. R.; Gasser, R. B. Genetic characterization of selected parasites from people with histories of gastrointestinal disorders using a mutation scanning-coupled approach. Electrophoresis 2013, 34, 1720-1728, doi: 10.1002/elps.201300100.

[11] Aula, O. P.; McManus, D. P. Molecular identification of Ancylostoma ceylanicum in the Philippines. 2020, 147, 17181722, doi: $10.1017 / \mathrm{s} 0031182020001547$.

[12] Colella, V.; Bradbury, R.; Traub, R. Ancylostoma ceylanicum. Trends in parasitology 2021, doi: 10.1016/j.pt.2021.04.013.

[13] Don, T. A.; Oksov, Y.; Lustigman, S.; Loukas, A. Saposin-like proteins from the intestine of the blood-feeding hookworm, Ancylostoma caninum. Parasitology 2007, 134, 427-436, doi: 10.1017/s003118200600148x.

[14] Balfour, E.; Zalka, A.; Lazova, R. Cutaneous larva migrans with parts of the larva in the epidermis. Cutis 2002, 69, 368370 .

[15] Brand, A.; Hawdon, J. M. Phosphoinositide-3-OH-kinase inhibitor LY294002 prevents activation of Ancylostoma caninum and Ancylostoma ceylanicum third-stage infective larvae. International journal for parasitology 2004, 34, 909914, doi: 10.1016/j.ijpara.2004.04.003.

[16] Hotez, P. J. Visceral and ocular larva migrans. Seminars in neurology 1993, 13, 175-179, doi: 10.1055/s-2008-1041123.

[17] Sato, H.; Suzuki, K. Gastrointestinal helminths of feral raccoons (Procyon lotor) in Wakayama Prefecture, Japan. The Journal of veterinary medical science 2006, 68, 311-318, doi: 10.1292/jvms.68.311.

[18] Shin, S. S.; Cha, D. J.; Cho, K. O.; Cho, H. S.; Choi, J. O.; Cho, S. H. Arthrostoma miyazakiense (Nematoda: Ancylo stomatidae) infection in raccoon dogs of Korea and experim ental transmission to dogs. The Korean journal of parasitolo gy 2007, 45, 121-128, doi: 10.3347/kjp.2007.45.2.121.

[19] Catalano, S.; Lejeune, M.; van Paridon, B.; Pagan, C. A.; Wasmuth, J. D.; Tizzani, P.; Duignan, P. J.; Nadler, S. A. Morphological variability and molecular identification of Uncinaria spp. (Nematoda: Ancylostomatidae) from grizzly and black bears: new species or phenotypic plasticity? The Journal of parasitology 2015, 101, 182-192, doi: 10.1645/14-621.1.

[20] Foster, G. W.; Cunningham, M. W.; Kinsella, J. M.; Forrester, D. J. Parasitic helminths of black bear cubs (Ursus americanus) from Florida. The Journal of parasitology 2004, 90, 173-175, doi: 10.1645/ge-127r. 
[21] Dikmans, G.; Goldberg, A. A note on Arthrocephalus lotoris (Schwartz, 1925) Chandler, 1942 and other roundworm parasites of the skunk, Mephitis nigra. Proc. Helminthol. Soc. Wash 1949, 16, 19-11, doi: 10.1017/CBO9781107415324.004.

[22] Ibáñez, N. [Peruvian helminthological fauna: Ancylostoma conepati Solanet, 1911. (Nematoda, Ancylostomatidae). Its presence in the North of Peru]. Boletin chileno de parasitologia 1968, 23, 142-145.

[23] Graber, M.; Blanc, J. P. [Ancylostoma duodenale (Dubini, 1843) Creplin, 1843 (Nematoda: Ancylostomidae), parasite of the spotted hyena Crocuta crocuta (Erxleben) in Ethiopia]. Revue d'elevage et de medecine veterinaire des pays tropicaux 1979, 32, 155-160, doi: 10.19182/remvt.8169.

[24] Engh, A. L.; Nelson, K. G.; Peebles, R.; Hernandez, A. D.; Hubbard, K. K.; Holekamp, K. E. Coprologic survey of parasites of spotted hyenas (Crocuta crocuta) in the Masai Mara National Reserve, Kenya. Journal of wildlife diseases 2003, 39, 224-227, doi: 10.7589/0090-3558-39.1.224.

[25] Colon, C. P.; Patton, S. Parasites of civets (Mammalia, Viverridae) in Sabah, Borneo: A coprological survey. Malayan Nat. J. 2012, 64, 87-94.

[26] Pourrut, X.; Diffo, J. L.; Somo, R. M.; Bilong Bilong, C. F.; Delaporte, E.; LeBreton, M.; Gonzalez, J. P. Prevalence of gastrointestinal parasites in primate bushmeat and pets in Cameroon. Veterinary parasitology 2011, 175, 187-191, doi: 10.1016/j.vetpar.2010.09.023.

[27] Dunbar, M. R.; McLaughlin, G. S.; Murphy, D. M.; Cunningham, M. W. Pathogenicity of the hookworm, Ancylostoma pluridentatum, in a Florida panther (Felis concolor coryi) kitten. Journal of wildlife diseases 1994, 30, 548-551, doi: 10.7589/0090-3558-30.4.548.

[28] Forrester, D. J.; Conti, J. A.; Belden, R. C. Parasites of the Florida panther (Felis concolor coryi). Proc. Helminthol. Soc. Wash. 1985, 52, 95-97.

[29] Miller, G. C.; Harkema, R. Parasites of Swift Fox (Vulpex velox) from South eastern Colorado South west Nat 1968 43, 476-479. Helminths of some wild mammals in the south eastern United States. Proc. Helminthol. Soc. Wash. 435: 118125 .

[30] Dos Santos, K.; Catenacci, L.; Pestelli, M.; Takahira, R.; Lopes, R.; Da Silva, R.;. First report of Ancylostoma buckleyi Le Roux and Biocca, 1957 (Nematoda: Ancylostomastidae) infecting Cerdocyon thous Linnaeus, 1766 (Mammalia: Canidae) from Brazil. Rev. Bras. Parasitol. 2003, 12, 179-181.

[31] Scioscia, N. P.; Beldomenico, P. M.; Denegri, G. M. Ancylost oma (Ancylostoma) buckleyi (Nematoda: Ancylostomatidae): new wild host and distribution expansion. Revista brasileira de parasitologia veterinaria $=$ Brazilian journal of veterinary parasitology: Orgao Oficial do Colegio Brasileiro de Parasito logia Veterinaria 2016, 25, 231-234, doi: 10.1590/s198429612016020.

[32] Smout, F. A.; Thompson, R. C.; Skerratt, L. F. First report of Ancylostoma ceylanicum in wild canids. International journal for parasitology. Parasites and wildlife 2013, 2, 173-177, doi: 10.1016/j.ijppaw.2013.04.003.

[33] Lahmar, S.; Boufana, B.; Ben Boubaker, S.; Landolsi, F. Intestinal helminths of golden jackals and red foxes from Tunisia. Veterinary parasitology 2014, 204, 297-303, doi: 10.1016/j.vetpar.2014.05.038.
[34] Takács, A.; Szabó, L.; Juhász, L.; Takács, A. A.; Lanszki, J.; Takács, P. T.; Heltai, M. Data on the parasitological status of golden jackal (Canis aureus L., 1758) in Hungary. Acta veterinaria Hungarica 2014, 62, 33-41, doi: 10.1556/AVet.2013.058

[35] Thatcher, V. E. Some Hookworms of the Genus Ancylostoma from Colombia and Panama. Proc. Helm. Soc. Wash. 1971, 38, 109-116.

[36] Youssefi, M.; Hoseini, S.; Hoseini, S.; Zaheri, B.; Tabari, M. A. First report of Ancylostoma tubaeforme in Persian Leopard (Panthera pardus saxicolor). Iranian journal of parasitology 2010, 5, 61-63.

[37] Xie, Y.; Hoberg, E. P.; Yang, Z.; Urban, J. F., Jr.; Yang, G. Ancylostoma ailuropodae n. sp. (Nematoda: Ancylostomati dae), a new hookworm parasite isolated from wild giant pand as in Southwest China. Parasites \& vectors 2017, 10, 277, doi: 10.1186/s13071-017-2209-2.

[38] Rendón-Franco, E.; Romero-Callejas, E.; Villanueva-García, C.; Osorio-Sarabia, D.; Muñoz-García, C. I. Cross transmission of gastrointestinal nematodes between captive neotropical felids and feral cats. Journal of zoo and wildlife medicine: official publication of the American Association of Zoo Veterinarians 2013, 44, 936-940, doi: 10.1638/2013-0015r2.1.

[39] Szafrańska, E.; Wasielewski, O.; Bereszyński, A. A faecal analysis of helminth infections in wild and captive wolves, Canis lupus L., in Poland. Journal of helminthology 2010, 84, 415-419, doi: 10.1017/s0022149x10000106.

[40] Saeed, I.; Maddox-Hyttel, C.; Monrad, J.; Kapel, C. M. Helmi nths of red foxes (Vulpes vulpes) in Denmark. Veterinary para sitology 2006, 139, 168-179, doi: 10.1016/j.vetpar.2006.02.015.

[41] Van Heerden, J.; Mills, M. G.; Van Vuuren, M. J.; Kelly, P. J.; Dreyer, M. J. An investigation into the health status and diseases of wild dogs (Lycaon pictus) in the Kruger National Park. Journal of the South African Veterinary Association 1995, 66, 18-27.

[42] Fu, Y.; Huang, Y.; Abuzeid, A. M. I.; Hang, J.; Yan, X.; Wang, M.; Liu, Y.; Sun, Y.; Ran, R.; Zhang, P.; et al. Prevalence and potential zoonotic risk of hookworms from stray dogs and cats in Guangdong, China. Veterinary parasitology, regional studie $s$ and reports 2019, 17, 100316, doi: 10.1016/j.vprsr.2019.100316.

[43] Rodríguez-Vivas, R. I.; Gutierrez-Ruiz, E.; Bolio-González, M. E.; Ruiz-Piña, H.; Ortega-Pacheco, A.; Reyes-Novelo, E.; Manrique-Saide, P.; Aranda-Cirerol, F.; Lugo-Perez, J. A. An epidemiological study of intestinal parasites of dogs from Yucatan, Mexico, and their risk to public health. Vector borne and zoonotic diseases (Larchmont, N. Y.) 2011, 11, 1141-1144, doi: $10.1089 /$ vbz.2010.0232.

[44] Liu, Y.; Zheng, G.; Alsarakibi, M.; Zhang, X.; Hu, W.; Lu, P.; Lin, L.; Tan, L.; Luo, Q.; Li, G. Molecular identification of Ancylostoma caninum isolated from cats in southern China based on complete ITS sequence. BioMed research international 2013, 2013, 868050, doi: 10.1155/2013/868050.

[45] Mahdy, M. A.; Lim, Y. A.; Ngui, R.; Siti Fatimah, M. R.; Choy, S. H.; Yap, N. J.; Al-Mekhlafi, H. M.; Ibrahim, J.; Surin, J. Prevalence and zoonotic potential of canine hookworms in Malaysia. Parasites \& vectors 2012, 5, 88, doi: 10.1186/1756-3305-5-88. 
[46] Ng-Nguyen, D.; Hii, S. F.; Nguyen, V. A.; Van Nguyen, T.; Van Nguyen, D.; Traub, R. J. Re-evaluation of the species of hookworms infecting dogs in Central Vietnam. Parasites \& vectors 2015,8 , 401, doi: 10.1186/s13071-015-1015-y.

[47] Wang, C. R.; Qiu, J. H.; Zhao, J. P.; Xu, L. M.; Yu, W. C.; Zhu, X. Q. Prevalence of helminthes in adult dogs in Heilong jiang Province, the People's Republic of China. Para sitology research 2006, 99, 627-630, doi: 10.1007/s 004 36-006-0219-7.

[48] Oliveira-Arbex, A. P.; David, E. B.; Oliveira-Sequeira, T. C.; Katagiri, S.; Coradi, S. T.; Guimarães, S. Molecular identifica tion of Ancylostoma species from dogs and an assessment of zoonotic risk in low-income households, São Paulo State, Bra zil. Journal of helminthology 2017, 91, 14-19, doi: 10.10 17/s0022149x15001145.

[49] Al-Jassim, K. B. N.; Mahmmod, Y. S. Epidemiological invest igation of gastrointestinal parasites in dog populations in Basr a province, Southern Iraq. 2017, 41, 1006-1013, doi: 10.1007/s12639-017-0926-2.

[50] Tun, S.; Ithoi, I.; Mahmud, R.; Samsudin, N. I.; Kek Heng, C.; Ling, L. Y. Detection of Helminth Eggs and Identification of Hookworm Species in Stray Cats, Dogs and Soil from Klang Valley, Malaysia. PloS one 2015, 10, e0142231, doi: 10.1371/journal.pone.0142231.

[51] Siyadatpanah, A.; Gholami, S.; Daryani, A.; Sarvi, S.; Sharif, M.; Seguel, M.; Boundenga, L.; Amouei, A.; Pagheh, A. S.; Rahimi, M. T.; et al. The Prevalence of Intestinal Helminths in Free-Ranging Canids of Mazandaran, Northern Iran. Iranian journal of parasitology 2019, 14, 563-571.

[52] Sulieman, Y.; Zakaria, M. A.; Pengsakul, T. Prevalence of intestinal helminth parasites of stray dogs in Shendi area, Sudan. Annals of parasitology 2020, 66, 115-118, doi: 10.17420/ap6601.246.

[53] Hailu, T.; Mulu, W.; Abera, B. Prevalence and determinant factors of hookworm infection among school age children in Jawe district, NorthWest Ethiopia. African health sciences 2019, 19, 2439-2445, doi: 10.4314/ahs.v19i3.18.

[54] Torres-Chablé, O. M.; García-Herrera, R. A.; HernándezHernández, M.; Peralta-Torres, J. A.; Ojeda-Robertos, N. F.; Blitvich, B. J.; Baak-Baak, C. M.; García-Rejón, J. E.; Machain-Wiliams, C. I. Prevalence of gastrointestinal parasites in domestic dogs in Tabasco, southeastern Mexico. Revista brasileira de parasitologia veterinaria=Brazilian journal of veterinary parasitology: Orgao Oficial do Colegio Brasileiro de Parasitologia Veterinaria 2015, 24, 432-437, doi: 10.1590/s1984-29612015077.

[55] La Torre, F.; Di Cesare, A.; Simonato, G.; Cassini, R.; Traver sa, D.; Frangipane di Regalbono, A. Prevalence of zoonotic helminths in Italian house dogs. Journal of infection in dev eloping countries 2018, 12, 666-672, doi: 10.3855/jidc.9865.
[56] Itoh, N.; Kanai, K.; Kimura, Y.; Chikazawa, S.; Hori, Y.; Hoshi, F. Prevalence of intestinal parasites in breeding kennel dogs in Japan. Parasitology research 2015, 114, 1221-1224, doi: 10.1007/s00436-015-4322-5.

[57] Pumidonming, W.; Salman, D.; Gronsang, D.; Abdelbaset, A. E.; Sangkaeo, K.; Kawazu, S. I.; Igarashi, M. Prevalence of gastrointestinal helminth parasites of zoonotic significance in dogs and cats in lower Northern Thailand. The Journal of vete rinary medical science 2017, 78, 1779-1784, doi: 10.1292/jvms.16-0293.

[58] Malgor, R.; Oku, Y.; Gallardo, R.; Yarzábal, I. High prevalence of Ancylostoma spp. infection in dogs, associated with endemic focus of human cutaneous larva migrans, in Tacuarembo, Uruguay. Parasite (Paris, France) 1996, 3, 131134, doi: 10.1051/parasite/1996032131.

[59] Hoggard, K. R.; Jarriel, D. M.; Bevelock, T. J.; Verocai, G. G. Prevalence survey of gastrointestinal and respiratory parasites of shelter cats in north eastern Georgia, USA. Veterinary parasitology, regional studies and reports 2019, 16, 100270, doi: 10.1016/j.vprsr.2019.100270.

[60] Loftin, C. M.; Donnett, U. B.; Schneider, L. G.; Varela-Stokes, A. S. Prevalence of endo-parasites in northern Mississippi shelter cats. Veterinary parasitology, regional studies and reports 2019, 18, 100322, doi: 10.1016/j.vprsr.2019.100322.

[61] Dubná, S.; Langrová, I.; Nápravník, J.; Jankovská, I.; Vadlejc h, J.; Pekár, S.; Fechtner, J. The prevalence of intestinal parasi tes in dogs from Prague, rural areas, and shelters of the Czech Republic. Veterinary parasitology 2007, 145, 120-128, doi: 10. 1016/j.vetpar.2006.11.006

[62] Traub, R. J.; Robertson, I. D.; Irwin, P.; Mencke, N.; Thomps on, R. C. Application of a species-specific PCR-RFLP to iden tify Ancylostoma eggs directly from canine faeces. Veterinary parasitology 2004, 123, 245-255, doi: 10.1016/j.vetpar.2004.05.026.

[63] Kladkempetch, D.; Tangtrongsup, S. Ancylostoma ceylanicu $m$ : The Neglected Zoonotic Parasite of Community Dogs in Thailand and Its Genetic Diversity among Asian Countries. 2020, 10, doi: 10.3390/ani10112154.

[64] Mulinge, E.; Njenga, S. M.; Odongo, D.; Magambo, J.; Zeyhl e, E.; Mbae, C.; Kagendo, D.; Kanyi, H.; Traub, R. J.; Wasser $\mathrm{m}$ ann, M.; et al. Molecular identification of zoonotic hookw orms in dogs from four counties of Kenya. Journal of helmin thology 2019, 94, e43, doi: 10.1017/s0022149x1900018x.

[65] Greenland, K.; Dixon, R.; Khan, S. A.; Gunawardena, K.; Kih ara, J. H.; Smith, J. L.; Drake, L.; Makkar, P.; Raman, S.; Sing $\mathrm{h}, \mathrm{S}$; ; et al. The epidemiology of soil-transmitted helmint- hs in Bihar State, India. PLoS neglected tropical diseases 201 5, 9, e0003790, doi: 10.1371/journal.pntd.0003790. 